\title{
Microsatellite DNA variation indicates low levels of genetic differentiation among cuttlefish (Sepia officinalis L.) populations in the English Channel and the Bay of Biscay
}

\author{
Katja Wolfram ${ }^{\text {a }}$, Felix Christopher Mark ${ }^{\mathrm{a}, \mathrm{b}, *}$, Uwe John $^{\mathrm{a}}$, Magnus Lucassen ${ }^{\mathrm{a}}$, Hans Otto Pörtner ${ }^{\mathrm{a}}$ \\ a Alfred Wegener Institute for Polar and Marine Research, Bremerhaven, Germany \\ b Zoology Department, Cambridge University, United Kingdom
}

Received 2 May 2006; received in revised form 5 August 2006; accepted 7 August 2006

Available online 9 August 2006

\begin{abstract}
Population substructure of the cuttlefish Sepia officinalis (Mollusca: Cephalopoda), as investigated by genetic variation of microsatellite loci, has been reported to be significantly extensive around the Iberian Peninsula with $F_{\mathrm{ST}}=0.061$ [Pérez-Losada, M., Guerra, A., Carvalho, G.R., Sanjuan, A., Shaw, P.W., 2002. Extensive population subdivision of the cuttlefish Sepia officinalis (Mollusca: Cephalopoda) around the Iberian Peninsula indicated by microsatellite DNA variation. Heredity $89,417-424]$ and panmictic in the semi-enclosed Adriatic Sea with $F_{\mathrm{ST}}=0.011$ [Garoia, F., Guarniero, I., Ramsak, A., Ungaro, N., Landi, M., Piccinetti, C., Mannini, P., Tinti, F., 2004. Microsatellite DNA variation reveals high gene flow and panmictic populations in the Adriatic shared stocks of the European squid and cuttlefish (Cephalopoda). Heredity 93, 166-174]. Yet, no verified genetic information on population substructure existed for the northern distribution range of this species in the English Channel and the Bay of Biscay.

So far, reproductive and migration behaviour and in vitro oxygen binding properties of haemocyanin have suggested the existence of separate populations in the English Channel and the Bay of Biscay. Examination of genetic variation at seven microsatellite loci within samples from the Bay of Biscay, the English Channel and the southern North Sea indicated low levels of genetic differentiation in this area but also a breakdown of free gene flow at highly significant average $F_{\mathrm{ST}}=0.018$. Although there is a considerable genetic exchange between populations of $S$. officinalis in the English Channel and the Bay of Biscay, they cannot be regarded as a single, freely interbreeding population. Earlier reported biological differences might thus be due to genetic variability between the populations.
\end{abstract}

(C) 2006 Elsevier Inc. All rights reserved.

Keywords: Cephalopod; Genetic differentiation; Microsatellites; Sepia officinalis; Bay of Biscay; English Channel

\section{Introduction}

Population substructure of the common European cuttlefish Sepia officinalis (Mollusca: Cephalopoda) has recently been investigated around the Iberian Peninsula and in the Adriatic Sea. Along the Iberian Atlantic and Mediterranean coast, microsatellite analysis revealed significant population subdivision (Pérez-Losada et al., 2002). By contrast, in the semi-enclosed Adriatic Sea, $S$. officinalis lives in a panmictic population

\footnotetext{
* Corresponding author. Physiologie mariner Tiere, Alfred-Wegener-Institut fuer Polar-und Meeresforschung, PO BOx 1201 61, 27515 Bremerhaven, Germany. Tel.: +49 4714831 1015; fax: +49 47148311149.

E-mail address: fmark@awi-bremerhaven.de (F.C. Mark).
}

(Garoia et al., 2004). No verified genetic information existed for the northern distribution range of this species (Denis and Robin, 2001), which extends through the Bay of Biscay and the English Channel into the North Sea. In the English Channel and adjacent waters and along the French Atlantic coast, S. officinalis is an important fishery resource and accounts for approximately $2.7 \%$ by weight of all French fishery landings (Wang et al., 2003).

In the Bay of Biscay, the English Channel and the North Sea, no geographical barriers exist, comparable to the Strait of Gibraltar or the Almería-Oran front in the Mediterranean which possibly account for population subdivision. Observations from reproductive and migration behaviour (Le Goff and Daguzan, 1991; Boucaud-Camou and Boismery, 1991) and results from physiological studies (Melzner et al., in preparation), however, 
suggest distinct $S$. officinalis populations in this area. According to different patterns of reproductive behaviour of $S$. officinalis from different European locations (Mediterranean Sea: Mangold, 1966; English Channel: Boucaud-Camou and Boismery, 1991; Bay of Biscay: Le Goff and Daguzan, 1991), separation of populations in the English Channel and the Bay of Biscay has been postulated by numerous authors (e.g., Le Goff and Daguzan, 1991; Dunn, 1999; Wang et al., 2003), although these relationships have never been confirmed. Annual migration patterns along the French Atlantic and English Channel coast appear strongly correlated with sea surface temperatures (Wang et al., 2003) and, furthermore, suggest differences between populations, especially as individuals tagged in the Bay of Biscay have not been relocated in the English Channel (Pawson, 1995). Thus, there is still a lack of evidence for migration of $S$. officinalis from the Bay of Biscay into the English Channel.

The aim of the present study was hence to apply neutral microsatellite DNA markers to evaluate the genetic relationships between $S$. officinalis specimens originating from various locations of its northern distribution range from the Bay of Biscay throughout the Channel into the North Sea.

\section{Materials and methods}

\subsection{Sampling}

Samples of $S$. officinalis eggs and adults were collected in the Bay of Biscay (La Rochelle, France, $n=58$; Biscay population, BP), at three different locations along the British and French coasts of the English Channel (Plymouth, UK, PLY, $n=12$; Dorset, UK, DS, $n=15$ and Luc-sur-Mer, France, LSM, $n=35$; English Channel population, ECP) and in the southern North Sea (Yerseke, Netherlands, $n=25$, North Sea population, NSP) between 2004 and 2005 (Fig. 1). Eggs were kept in the institute's aquarium systems until animals hatched. A fourth population from Southern Portugal (Faro, $n=4$, Southern Portugal population, SPP) was used as a reference.

Samples of arm and/or mantle musculature were either taken freshly from fully anaesthetized hatchlings ( $2 \%$ absolute ethanolcontaining seawater), from anaesthetized adult specimens $(10 \mathrm{~g} / \mathrm{L}$ $\mathrm{MgCl}_{2}$-containing seawater) or from frozen or ethanol $(40 \%$ absolute) preserved samples. Anaesthetized animals were killed after the sampling procedure.

\subsection{DNA extraction and microsatellite analyses}

Individual genomic DNA was obtained following the Qiagen ${ }^{\circledR}$ procedure (DNeasy kit), and individuals were screened for variation at each of the seven polymorphic microsatellite loci (Sofl to Sof7) previously described by Shaw and Pérez-Losada (1999). Primers were synthesised by Invitrogen ${ }^{\mathrm{TM}}$ Life Technologies (reverse primer) and Applied Biosystems UK (forward primer, 5' end-labelled with FAM [Sof1, Sof4, Sof7], HEX [Sof2, Sof5] and NED [Sof3, Sof6]).

PCR reactions with the labelled primers were performed with HotMaster $^{\circledR}$ Taq Polymerase (Eppendorf) as follows: $120 \mathrm{~s}$ at $94{ }^{\circ} \mathrm{C}$, then 21 cycles of $30 \mathrm{~s}$ at $94{ }^{\circ} \mathrm{C}, 30 \mathrm{~s}$ at the specific annealing temperature (see below) in a touchdown gradient of $0.3 \mathrm{~s} /{ }^{\circ} \mathrm{C}$ and $60 \mathrm{~s}$ at $72{ }^{\circ} \mathrm{C}$, then 26 cycles of $30 \mathrm{~s}$ at $94{ }^{\circ} \mathrm{C}, 30 \mathrm{~s}$ at $49^{\circ} \mathrm{C}$ and $60 \mathrm{~s}$ at $72{ }^{\circ} \mathrm{C}$, finally $10 \mathrm{~min}$ at $72{ }^{\circ} \mathrm{C}$ and cooling at $10{ }^{\circ} \mathrm{C}$ until PCR products were removed from the thermocycler (Eppendorf Mastercycler gradient). Optimal annealing temperatures determined in preliminary tests were $56{ }^{\circ} \mathrm{C}$ for amplification of loci Sof1, Sof2, Sof3 and Sof7 and $61{ }^{\circ} \mathrm{C}$ for loci Sof4, Sof5 and Sof6.

HotMaster $^{\circledR}$ Taq Polymerase PCR reaction mixtures contained $1 \mu \mathrm{L}$ of template $(10 \mathrm{ng}), 0.15 \mu \mathrm{L}$ primers (50 pmol/ $\mu \mathrm{L})$, Taq Buffer (Eppendorf) with $1.5 \mathrm{mM} \mathrm{Mg}^{2+}$, $0.12 \mu \mathrm{L}$ of nucleotides (each $25 \mathrm{mM}$ ), $0.075 \mu \mathrm{L}$ of Taq Polymerase $(5 \mathrm{U} / \mu \mathrm{L})$ and were brought to a final volume of $15 \mu \mathrm{L}$ with distilled water. Amplified products were diluted when necessary and pooled according to their $5^{\prime}$ end-labels. $15 \mu \mathrm{L}$ of HiDi-Formamide, $0.5 \mu \mathrm{L}$ of GeneScan ${ }^{\mathrm{TM}} 500 \mathrm{ROX}^{\mathrm{TM}}$ size standard and $0.5 \mu \mathrm{L}$ of (pooled) amplified product then were run on an ABI PRISM 3130 XL Genetic Analyser and were analysed using the Genemapper v.3.7 software (Applied Biosystems).

\subsection{Data conversion}

For statistical analysis of genetic variability among $S$. officinalis from North Sea, English Channel, Bay of Biscay and Southern Portugal populations, allele scores of 70 individuals from Faro (Southern Portugal population, SPP), kindly provided by M. Pérez-Losada, were used. Due to different PCR profiles in both studies an adjustment of data was necessary to compensate for longer final elongation periods in each cycle $(60 \mathrm{~s})$ and an additional elongation period $(10 \mathrm{~min})$ at the end of the reaction in the present study (see above). In contrast, data provided by M. Pérez-Losada were collected running PCRs with only $10 \mathrm{~s}$ final elongation steps in each cycle (Shaw and Pérez-Losada, 1999). To simulate a 3'-A-extension evoked by Taq-Polymerase and to bring both repeat rhythms into line, allele sizes of M. Pérez-Losada et al. were extended by one (Sof3, Sof5) or two base pairs (Sof6, Sof7).

Locus Sof3 has been reported to display two parallel arrays of alleles differing by one base pair (Shaw and Pérez-Losada, 1999) and was omitted in the study of Garoia et al. (2004). A biallelic character of Sof3 was also revealed in the current study; therefore, the sequences of several Sof 3 clones were determined to reveal the nature of the differences prior to adjustment and binning of the two arrays (cf. Shaw and Pérez-Losada, 1999; Pérez-Losada et al., 2002).

\subsection{Statistical analysis of data}

Genetic polymorphism at the seven microsatellite loci was estimated as the mean number of alleles per locus $\left(N_{\mathrm{a}}\right)$, observed $\left(H_{\mathrm{O}}\right)$ and expected heterozygosity $\left(H_{\mathrm{E}}\right) . H_{\mathrm{E}}$ was calculated using the algorithm of Levene (1949) implemented in the Popgene v.1.32 software (http://www.ualberta.ca/ fyeh/download.htm). Levene's correction for small sample sizes is identical with Nei's (1972) unbiased expected heterozygosity, which was used by the GENEPOP v.3.4 software (Raymond and Rousset, 


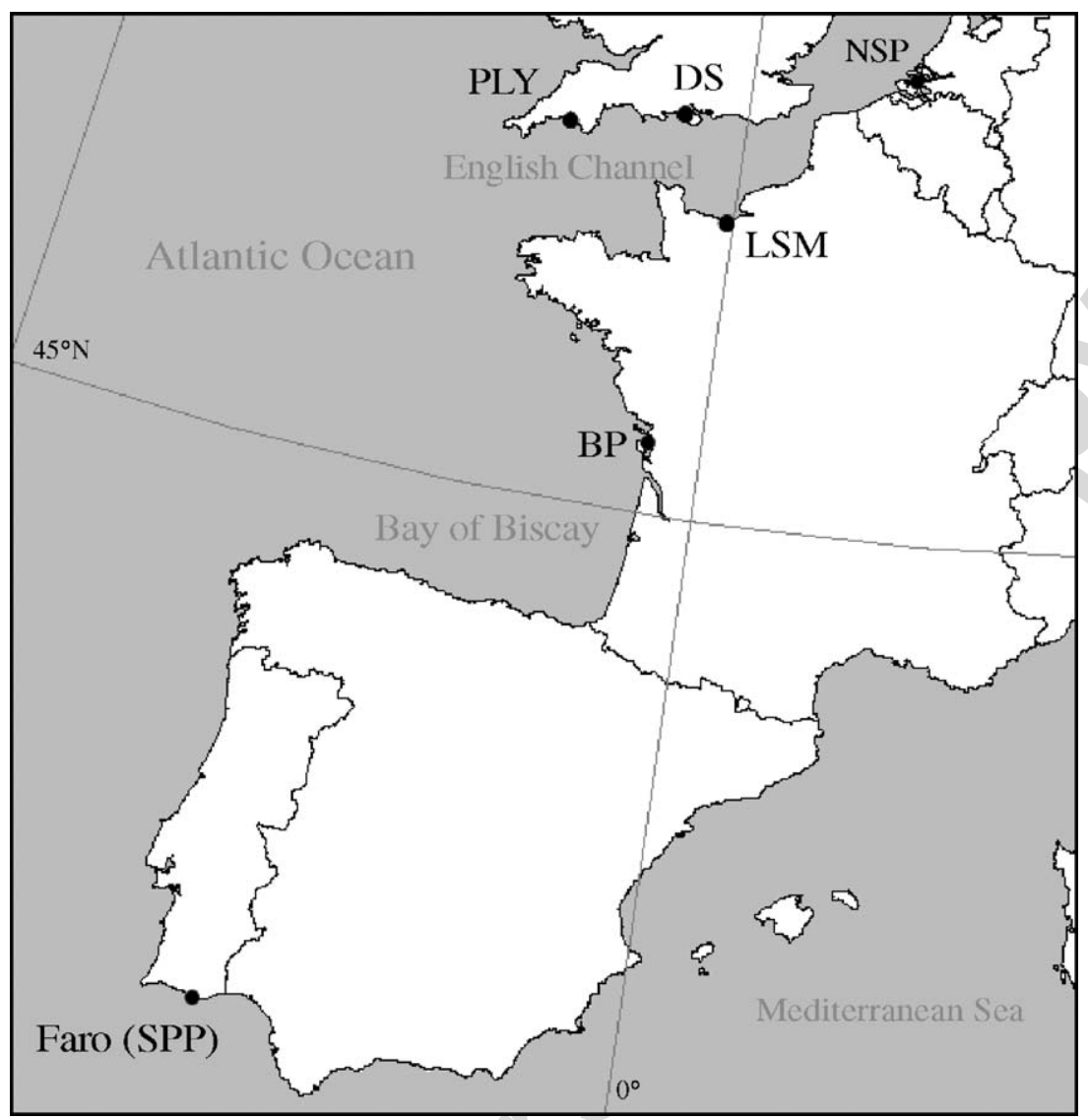

Fig. 1. Samples of $S$. officinalis collected in the southern North Sea (North Sea population, NSP, $n=25)$, in the English Channel (PLY, DS and LSM =English Channel population, ECP, $n=63$ ) and in the Bay of Biscay (Biscay population, BP $n=58$ ). Samples of $S$. officinalis of the Southern Portugal population off Faro (SPP, $n=4$ ) were supplemented by microsatellite data from 70 additional individuals kindly provided by M. Pérez-Losada.

1995) to test for significant deviations from Hardy-Weinberg (henceforth HW) equilibrium by Fisher's exact test. The level of significance for this test was determined by Markov chain method by the software (10,000 dememorizations, 100 batches, 5000 iterations per batch). Genotypes at all pairs of loci within each sample were tested for genotypic disequilibrium (linkage disequilibrium) using the Arlequin v.2.000 software package (1000 permutations, 10 initial conditions, http://anthropologie. unige.ch/arlequin/).

Simple genic differentiation among samples (heterogeneity of allele frequencies) was tested using the Fisher's exact test implemented in the GENEPOP v.3.4 software package with level of significance determined by the Markov chain method (10,000 dememorizations, 100 batches, 5000 iterations per batch) (Raymond and Rousset, 1995).

The genetic relationships between samples were estimated using statistics based on an infinite allele model (IAM, Kimura and Crow, 1964) as well as using statistics based on an alternative, stepwise mutation model (SMM, Kimura and Ohta, 1978). As it is still a matter of debate which is the most suitable statistic model to describe genetic variation among samples (see Goodman, 1997; Valsecchi et al., 1997; Gaggiotti et al., 1999; Hardy et al., 2003), both models were used to analyse the data of this study: The IAM-based $F_{\mathrm{ST}}$ (Wright, 1969), which can also be estimated by $\theta$ (Cockerham and Weir, 1984), and the SMM- based $R_{\mathrm{ST}}$ (Slatkin, 1995) were calculated pairwise for all four populations using the Arlequin software v.2.000. $F_{\mathrm{ST}}$ and $R_{\mathrm{ST}}$ values were tested for significant departure from zero using permutation procedures implemented in Arlequin v.2.000. To adjust for multiple comparisons, sequential Bonferroni corrections were applied when necessary (Rice, 1989).

It has been pointed out in several reviews (Balloux and LugonMoulin, 2002, Gaggiotti et al., 1999) that in the absence of a strict $\mathrm{SMM}$ and low levels of population divergence, $F_{\mathrm{ST}}$-based estimates are better than $R_{\mathrm{ST}}$, moreover so when sample sizes are moderate or small $\left(n_{\mathrm{s}}<10\right)$ and the number of loci scored is low $\left(n_{1}<20\right)$. Garoia et al. (2004) performed allele size permutation tests and also concluded that $F_{\mathrm{ST}}$ is the more appropriate estimator for weak population structures as seen for $S$. officinalis in the Adriatic Sea. This is also the case in the present study; we will therefore present both $F_{\mathrm{ST}}$ and $R_{\mathrm{ST}}$ in Results, but only discuss the $F_{\text {ST }}$ indices.

The unbiased distances of Nei (1978) were used to evaluate genetic relationships between the four Sepia populations assuming the IAM and calculated using the TFGPA v.1.3 software (Miller, 1997) and the Phylip v.3.6 software package (both available at http://evolution.genetics.washington.edu/phylip. html), respectively. Estimates of the effective number of migrants per generation between the sampling sites were calculated using the private allele method (Barton and Slatkin, 
1986) implemented in the GENEPOP software. UPGMA trees were calculated using the TFPGA and Phylip software and edited with MEGA 3 (Kumar et al., 2004).

\section{Results}

\subsection{Bi-allelic character of Locus Sof3}

The difference between both Sof3-arrays was identified not to be part of the trinucleotide repeat motif (cf. Fig. 2). Both arrays differed by two adenines in a stretch of either three or five adenines after the last motif repeat unit. Thus, all Sof3 data were adjusted by subtracting the entire adenine stretch (i.e., "array 1" three adenines, "array 2" five adenines; see Fig. 2). They were then binned to produce a single 'synthetic' data set according to Pérez-Losada et al. (2002).

\subsection{Microsatellite variability within samples}

Allele size and estimates of genetic variability at the seven microsatellite loci screened within 146 specimens of $S$. officinalis in the North Sea, the English Channel and the Bay of Biscay and 74 specimens from the Southern Portugal population off Faro are shown in Table 1. Genetic withinsample variability was moderate across the three northern sampling sites: mean number of alleles per locus $\left(N_{\mathrm{a}}\right)$ ranged between 6.0 and 7.6 (mean 7.0), and mean observed $\left(H_{\mathrm{O}}\right)$ and unbiased expected heterozygosity $\left(H_{\mathrm{E}}\right)$ ranged between 0.497 and 0.569 (mean 0.531), and 0.556 and 0.584 (mean 0.575), respectively. The North Sea sample displayed slightly lower $N_{\mathrm{a}}$, $H_{\mathrm{O}}$ and $H_{\mathrm{E}}$ than the samples from the English Channel and the Bay of Biscay, which may be an effect of a reduced sampling size (NSP $n=25$, compared to $n=63$ and 58 at ECP and BP, respectively). Within-sample variability in the Southern Portugal population off Faro was markedly higher with $N_{\mathrm{a}}$ being 10.9, and $H_{\mathrm{O}}$ and $H_{\mathrm{E}} 0.701$ and 0.795 , respectively.

In 16 single locus tests observed heterozygosities were lower and in 11 higher than those expected. In one test observed and expected heterozygosity matched. Thirteen significant departures from HW expectations were revealed by these 28 single locus tests. Twelve deviations were due to heterozygote deficits, one was caused by a heterozygote excess (Sof5 at ECP). After sequential Bonferroni correction, only six tests associated with locus Sof4 (all samples) and with Sof3 and Sof7 (both only at SPP) remained significant for a deficit of heterozygotes with $P<0.001$ (Table 1). Despite the apparent conformity of most loci to HW expectations (cf. Table 1), multi-locus tests resulted in highly significant $(P<0.001)$ heterozygote deficits for all samples. A similar observation was previously reported by Pérez-Losada et al. (2002).

Significant genotypic linkage disequilibrium was revealed by exact tests of all 21 pairs of loci within the four samples. After sequential Bonferroni correction was applied to adjust the level of significance for multiple comparisons, only five out of 84 comparisons led to significant values: Sof1-Sof5 at ECP and BP, Sof1-Sof7 at SPP, Sof5-Sof7 at BP and Sof4-Sof6 at ECP (all $P<0.001$ ). Except for the highly significant tests associated with the Sof1-Sof5-Sof7 group there was no indication for statistical linkage among the majority ( $94 \%, 79$ cases out of 84 ) of the microsatellite loci examined in this study. A certain degree of statistical linkage between the three loci was previously suggested by Pérez-Losada et al. (2002) for S. officinalis samples around the Iberian Peninsula. Garoia et al. (2004) excluded locus Sof5 (and Sof3) from their study and reported no significant linkage disequilibrium between any pairs of the remaining five loci.

To evaluate potential effects of linkage disequilibrium in the present study, statistical analysis of data was performed for multiple scenarios: (a) for all seven microsatellite loci, (b) excluding Sof1, (c) excluding Sof1 and Sof5, (d) excluding Sof1 and Sof7 and (e) excluding Sof1, Sof5 and Sof7. For reasons of clarity, only results of scenario (a) and (e) will be presented in the following.

\subsection{Population subdivision}

Exact tests for homogeneity of allelic frequencies revealed highly significant heterogeneity for all pairwise comparisons between the three northern populations (NSP, ECP and BP) and the Southern Portugal population, both at individual loci and over all loci combined $(P<0.001)$.

Exact test for homogeneity of individual loci across the three northern populations indicated significant differences only at loci Sof2 and Sof7 for NSP-ECP (both $P<0.01$ ), loci Sof1 $(P<0.01)$ and Sof6 $(P<0.001)$ for ECP-BP and loci Sof1 $(P<0.05)$, Sof2 $(P<0.01)$ and Sof7 $(P<0.05)$ for NSP-BP. Over all loci combined significant heterogeneity was shown for NSPECP and NSP-BP $(P<0.01)$ and ECP-BP $(P<0.001)$.

Pairwise comparisons of among-sample variability resulted in highly significant $F_{\mathrm{ST}}$ values $(P<0.001$, after sequential Bonferroni correction) for all pairs of samples (Table 2) and all seven loci. $F_{\mathrm{ST}}$ values for comparisons among the northern sampling sites ranged between 0.012 and 0.021 for all loci (mean 0.018) and between 0.116 and 0.119 (mean 0.117) for comparisons of the northern populations with the Southern Portugal population, respectively. 
Table 1

Genetic variation at seven microsatellite loci in S. officinalis samples from the southern North Sea, the English Channel, the Bay of Biscay and off the southern Portuguese coast (Faro)

\begin{tabular}{|c|c|c|c|c|c|c|}
\hline \multirow[t]{2}{*}{ Locus } & \multicolumn{6}{|l|}{ Sampling site } \\
\hline & $\begin{array}{l}\text { North Sea } \\
\text { (NSP) } n=25\end{array}$ & $\begin{array}{l}\text { English Channel } \\
(\mathrm{ECP}) n=63\end{array}$ & $\begin{array}{l}\text { Bay of Biscay } \\
\text { (BP) } n=58\end{array}$ & $\begin{array}{l}\text { Southern Portugal } \\
\text { (SPP) } n=74\end{array}$ & Mean northern samples & Mean all samples \\
\hline \multicolumn{7}{|l|}{ Sof1 } \\
\hline Allele size & $220-256$ & $220-259$ & $220-259$ & $220-259$ & $220-259$ & $220-259$ \\
\hline$N_{\mathrm{a}}$ & 5 & 9 & 8 & 10 & $7.3(2.1)$ & $8.0(2.2)$ \\
\hline$H_{\mathrm{O}}$ & 0.480 & 0.810 & 0.793 & 0.824 & $0.694(0.186)$ & $0.727(0.165)$ \\
\hline$H_{\mathrm{E}}$ & 0.540 & 0.733 & 0.767 & 0.821 & $0.680(0.122)$ & $0.715(0.122)$ \\
\hline dHWE & ns & ns & ns & ns & & \\
\hline \multicolumn{7}{|l|}{ Sof2 } \\
\hline Allele size & $148-181$ & $157-178$ & $154-181$ & $160-184$ & $148-181$ & $148-184$ \\
\hline$N_{\mathrm{a}}$ & 9 & 8 & 9 & 9 & $8.7(0.6)$ & $9.0(0.0)$ \\
\hline$H_{\mathrm{O}}$ & 0.800 & 0.603 & 0.672 & 0.797 & $0.692(0.100)$ & $0.718(0.097)$ \\
\hline$H_{\mathrm{E}}$ & 0.797 & 0.593 & 0.674 & 0.842 & $0.688(0.103)$ & $0.726(0.114)$ \\
\hline dHWE & ns & ns & ns & ns & & \\
\hline \multicolumn{7}{|l|}{ Sof3 } \\
\hline Allele size & $177-204$ & $171-204$ & $174-204$ & $168-216$ & $171-204$ & $168-216$ \\
\hline$N_{\mathrm{a}}$ & 10 & 11 & 11 & 15 & $10.7(0.6)$ & $11.8(2.2)$ \\
\hline$H_{\mathrm{O}}$ & 0.760 & 0.714 & 0.759 & 0.730 & $0.744(0.026)$ & $0.741(0.023)$ \\
\hline$H_{\mathrm{E}}$ & 0.746 & 0.825 & 0.782 & 0.855 & $0.784(0.039)$ & $0.802(0.048)$ \\
\hline dHWE & ns & ns & ns & $* * *$ & & \\
\hline \multicolumn{7}{|l|}{ Sof4 } \\
\hline Allele size & $136-157$ & $136-160$ & $130-157$ & $133-163$ & $130-160$ & $130-163$ \\
\hline$N_{\mathrm{a}}$ & 6 & 8 & 8 & 11 & $7.3(1.2)$ & $8.3(2.1)$ \\
\hline$H_{\mathrm{O}}$ & 0.240 & 0.302 & 0.155 & 0.500 & $0.232(0.074)$ & $0.299(0.147)$ \\
\hline$H_{\mathrm{E}}$ & 0.474 & 0.446 & 0.539 & 0.764 & $0.486(0.048)$ & $0.556(0.144)$ \\
\hline dHWE & $* * *$ & $* * *$ & $* * *$ & $* * *$ & & \\
\hline \multicolumn{7}{|l|}{ Sof5 } \\
\hline Allele size & $126-144$ & $126-192$ & $126-192$ & $126-210$ & $126-192$ & $126-210$ \\
\hline$N_{\mathrm{a}}$ & 3 & 5 & 4 & 13 & $4.0(1.0)$ & $6.3(4.6)$ \\
\hline$H_{\mathrm{O}}$ & 0.400 & 0.694 & 0.466 & 0.757 & $0.520(0.154)$ & $0.579(0.173)$ \\
\hline$H_{\mathrm{E}}$ & 0.496 & 0.586 & 0.466 & 0.756 & $0.516(0.062)$ & $0.576(0.130)$ \\
\hline dHWE & $\mathrm{ns}$ & $\mathrm{ns}$ & $\mathrm{ns}$ & ns & & \\
\hline \multicolumn{7}{|l|}{ Sof6 } \\
\hline Allele size & $217-247$ & $223-247$ & $223-259$ & $223-259$ & $217-259$ & $217-259$ \\
\hline$N_{\mathrm{a}}$ & 6 & 8 & 10 & 13 & $8.0(2.0)$ & $9.3(3.0)$ \\
\hline$H_{\mathrm{O}}$ & 0.600 & 0.656 & 0.702 & 0.811 & $0.653(0.051)$ & $0.692(0.089)$ \\
\hline$H_{\mathrm{E}}$ & 0.586 & 0.655 & 0.667 & 0.850 & $0.636(0.044)$ & $0.690(0.113)$ \\
\hline dHWE & ns & ns & ns & ns & & \\
\hline \multicolumn{7}{|l|}{ Sof7 } \\
\hline Allele size & $167-176$ & $170-176$ & $170-176$ & $170-182$ & $167-176$ & $167-182$ \\
\hline$N_{\mathrm{a}}$ & 3 & 3 & 3 & 5 & $3.0(0.0)$ & $3.5(1.0)$ \\
\hline$H_{\mathrm{O}}$ & 0.200 & 0.206 & 0.138 & 0.487 & $0.181(0.038)$ & $0.258(0.156)$ \\
\hline$H_{\mathrm{E}}$ & 0.254 & 0.254 & 0.192 & 0.676 & $0.233(0.036)$ & $0.344(0.223)$ \\
\hline dHWE & ns & ns & ns & $* * *$ & & \\
\hline \multicolumn{7}{|l|}{ Mean } \\
\hline$N_{\mathrm{a}}$ & $6.0(2.7)$ & $7.4(2.6)$ & $7.6(3.0)$ & $10.9(3.3)$ & $7.0(0.9)$ & $8.0(2.1)$ \\
\hline$H_{\mathrm{O}}$ & $0.497(0.237)$ & $0.569(0.226)$ & $0.526(0.280)$ & $0.701(0.145)$ & $0.531(0.036)$ & $0.573(0.090)$ \\
\hline$H_{\mathrm{E}}$ & $0.556(0.181)$ & $0.584(0.189)$ & $0.584(0.207)$ & $0.795(0.066)$ & $0.575(0.016)$ & $0.630(0.111)$ \\
\hline
\end{tabular}

Allele size (in base pairs), number of alleles $\left(N_{\mathrm{a}}\right)$, observed heterozygosity $\left(H_{\mathrm{O}}\right)$, unbiased expected heterozygosity $\left(H_{\mathrm{E}}\right.$ after Levene, 1949$)$ and significant deviations from Hardy-Weinberg equilibrium (dHWE) are given.

Significance of deviations from Hardy-Weinberg expectations within loci after sequential Bonferroni correction: $* * * P<0.001$; ns, not significant. 
Table 2

Pairwise estimates of $F_{\mathrm{ST}}$ and migrants per generation (below diagonal) and the unbiased distance of Nei (1978, above diagonal, in italics) between samples of $S$. officinalis

\begin{tabular}{|c|c|c|c|c|c|c|c|c|}
\hline & & \multicolumn{2}{|c|}{ North Sea (NSP) } & \multicolumn{2}{|c|}{ English Channel (ECP) } & \multicolumn{2}{|c|}{ Bay of Biscay (BP) } & Southern Portugal (SPP) \\
\hline \multirow[t]{4}{*}{$\mathrm{a}$} & North Sea & - & & 0.0274 & & 0.0295 & & 0.3159 \\
\hline & English Channel & $0.02055 * * *$ & 4.75 & - & & 0.0169 & & 0.3035 \\
\hline & Bay of Biscay & $0.02156^{* * *}$ & 5.76 & $0.01188^{* * *}$ & 4.03 & - & & 0.2934 \\
\hline & Southern Portugal & $0.11618 * * *$ & 2.68 & $0.11857^{* * *}$ & 2.50 & $0.11618 * * *$ & 2.73 & - \\
\hline \multirow[t]{4}{*}{$\mathrm{b}$} & North Sea & - & & 0.0346 & & 0.0272 & & 0.3757 \\
\hline & English Channel & $0.01997^{*}$ & 6.28 & - & & 0.0174 & & 0.3919 \\
\hline & Bay of Biscay & $0.01399^{*}$ & 6.09 & $0.00976^{*}$ & 4.07 & - & & 0.3709 \\
\hline & Southern Portugal & $0.10415^{* * *}$ & 2.47 & $0.11896^{* * *}$ & 2.59 & $0.10324 * * *$ & 3.06 & - \\
\hline
\end{tabular}

a: All seven microsatellite loci included.

b: Only microsatellite loci included which do not display significant linkage disequilibrium (Sof2, Sof3, Sof4 and Sof6).

Significance of $F_{\mathrm{ST}}$ after sequential Bonferroni correction is denoted as follows: ${ }^{*} P<0.05, * * * P<0.001$.

Exclusion of potentially linked loci Sof1-Sof5-Sof7 lead to $F_{\mathrm{ST}}$ values significant at $P<0.05$ for the three northern populations (NSP, ECP and BP). For loci Sof2, Sof3, Sof4 and Sof6 exclusively, $F_{\mathrm{ST}}$ values among the northern populations ranged between 0.010 and 0.020 (mean 0.015 ) and from 0.103 to 0.119 (mean 0.109) for comparisons with the Southern Portugal population, respectively. $F_{\mathrm{ST}}$ hence slightly decreased for the three northern samples. Overall, however, $F_{\mathrm{ST}}$ remained much lower for comparisons across the northern $S$. officinalis sampled in the North Sea, the English Channel and the Bay of Biscay than for comparisons between either of them with specimens from the Southern Portugal sample.

Migrants between the populations reflected $F_{\mathrm{ST}}$ values, with mean migrant values of 4.84 per generation for pairwise comparison of ECP, BP and NSP and mean migrant values of 2.67 for comparison of either Northern Population with the Southern Portugal population (Table 2). Migrants were highest among the subpopulations of the English Channel population (ECP) with 8.14 migrants per generation, thus reflecting the close relationship among them.

\subsection{Genetic relationships among samples}

A UPGMA dendrogram constructed from the unbiased distance of Nei (1978) is given in Fig. 3 (values given in Table 2). The three northern sampling areas North Sea, the English Channel and the Bay of Biscay cluster together and exhibit a large genetic distance to the Southern Portugal samples with $100 \%$ bootstrap support for all but the North Sea-English Channel branch, which was moderately supported by $63 \%$ $(10,000$ permutations). Trees based on the same distance mea- sure, but exclusively taking unlinked loci into account, exhibited the same topology as shown for all loci in Fig. 3.

\section{Discussion}

\subsection{Within-sample genetic variability}

All loci screened in this study have been proven polymorphic (after Hartl and Clark, 1997) with the most frequent allele occurring in less than $95 \%$ of genotypes (allele 173 bp at Sof7, maximum allele frequency $=0.897$ in ECP). Despite this, polymorphism is noticeably reduced within samples from the North Sea, the English Channel and the Bay of Biscay compared to samples around the Iberian Peninsula. The mean number of alleles for the northern samples was only $N_{\mathrm{a}}=7.0$, but was $N_{\mathrm{a}}=9.6$ for the Iberian samples of Pérez-Losada et al. (2002). Even at single locus level, reduced polymorphism became obvious for each locus compared to the Iberian cuttlefish. To a lesser degree, this is also reflected in the comparison between the three northern sampling sites and the Southern Portugal samples, which were chosen as reference samples in the current study.

When loci Sof3 and Sof5 were excluded for the three northern sampling sites of the present study, a rather low mean number of alleles $\left(N_{\mathrm{a}}=6.9\right)$ was found that was comparable to the findings of Garoia et al. (2004), who reported a mean number of 6.4 alleles per locus for the panmictic Adriatic cuttlefish.

Deviations from the HW equilibrium by an excess of homozygote genotypes have been reported to be a common phenomenon within cephalopod populations (Shaw and PérezLosada, 1999; Pérez-Losada et al., 2002; Garoia et al., 2004, present study). For Iberian $S$. officinalis, non-amplifying alleles

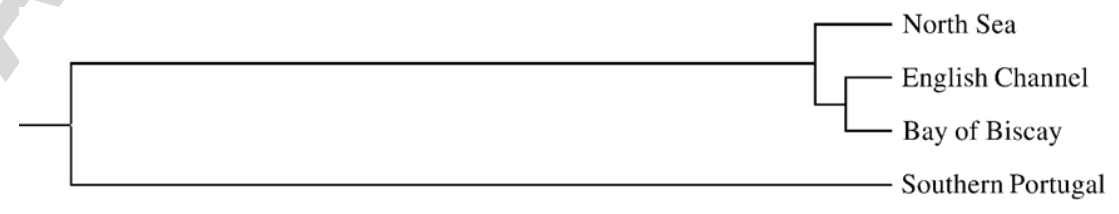

0.05

Fig. 3. UPGMA tree showing relationships among the four $S$. officinalis sampling sites based on the unbiased distance of Nei (1978) calculated from microsatellite data of seven loci. Bootstrap support is 63 for the North Sea-English Channel branch and 100 for the other branches (10,000 replications). 
were suggested and confirmed by mating assays to account for an observed heterozygote deficit at loci Sof4 and Sof7 (Pérez-Losada et al., 2002). For Adriatic cuttlefish, homozygote excesses were related to null alleles as well as to sampling effects due to a temporal heterogeneity of migrating cohorts (Garoia et al., 2004). As cuttlefish from the sampling sites of the present study clearly display seasonal patterns of reproduction and migration (see below), sampling bias caused by temporal heterogeneity is less probable to explain the observed heterozygote deficiencies at locus Sof4, Sof7 and Sof3. Profound genetic within-sample heterogeneity as suggested based on different biological cycles in the Bay of Biscay (Le Goff and Daguzan, 1991; Dunn, 1999) is also not expected to apply to the present data set (for reasons explained below). More likely, the overestimation of homozygosity in the present study may result from mutations in the primer sequence, although difficulties of PCR amplification were related to individual samples rather than to single loci and assigned to denaturation of template DNA.

Exclusion of potentially linked loci Sof1-Sof5-Sof7 noticeably altered neither the IAM-based fixation index nor the unbiased genetic distance of Nei (1978).

\subsection{Population subdivision}

The exact test of genic differentiation weights rare alleles more heavily than other estimators and is thus considered to be most sensitive to detect even weak population differentiation (Garoia et al., 2004). Estimation of spatial heterogeneity by exact tests of allele frequency homogeneity in the current study, however, only indicated a significant difference between all four samples in an overall test, while at the level of individual loci most comparisons (14/21) between the three northern samples were not significantly divergent at the 5\% level. Individual loci thus contributed differently to the overall sample heterogeneity among the three northern samples.

Genetic variation revealed by $F_{\mathrm{ST}}$ assuming the infinite allele model indicated minor, but highly significant levels of genetic variability among individuals sampled in the southern North Sea, the English Channel and the Bay of Biscay (mean $\left.F_{\mathrm{ST}}=0.018, P<0.001\right)$ and an extensive genetic variability between either of them and individuals sampled in the NE Atlantic off South Portugal (mean $F_{\mathrm{ST}}=0.117, P<0.001$ ).

Genetic divergence estimated by $F_{\mathrm{ST}}$ among the North Sea, the English Channel and the Bay of Biscay cuttlefish in the present study thus is comparable to those reported for neighbouring sampling sites along the Iberian Atlantic coast $(\theta=0.014-0.022$, Pérez-Losada et al., 2002) and those in the panmictic Adriatic Sea population $\left(F_{\mathrm{ST}}=0.018-0.022\right.$, Garoia et al., 2004). $F_{\mathrm{ST}}$ values for $S$. officinalis between the three northern sampling sites and the Southern Portugal samples are comparable to those $\theta$ reported for $S$. officinalis on either side of the Iberian Peninsula: $F_{\mathrm{ST}}$ for the comparison between cuttlefish from Lisbon and Alicante, separated by the Strait of Gibraltar and the Almería-Oran front, was $\theta=0.0114(P<0.001$, Pérez-Losada et al., 2002).

A much larger distance between the three northern sites (ECP, BP and NSP) and Southern Portugal than among ECP, BP and NSP is also suggested by the dendrogram of Nei's unbiased distance presented in Fig. 3.

\subsection{Opportunities for genetic exchange among $S$. officinalis in the English Channel and the Bay of Biscay}

The findings in the present study indicate extensive gene flow among weakly structured cuttlefish populations from the Bay of Biscay into the North Sea and thus in part disagree with the common assumption of strictly separate populations of $S$. officinalis in the English Channel and Bay of Biscay, which has been suggested by numerous authors (e.g., Le Goff and Daguzan, 1991; Pawson, 1995; Dunn, 1999; Wang et al., 2003). The arguments brought forward by these authors should thus be reconsidered in the light of possible genetic exchange between populations of $S$. officinalis in the English Channel and Bay of Biscay that is indicated by the present study.

Cuttlefish landings in the English Channel and adjacent waters analysed by Wang et al. (2003) indicated a potential mergence of high abundance centres in the English Channel and in offshore deep waters along the northern French Atlantic coast as a result of extensive migrations. The authors assumed that all cuttlefish present offshore the northern French Atlantic coast in winter originate from the English Channel only, although these centres of high abundance may move further south in offshore deep waters along the western French Atlantic coast in winter. Wang et al. (2003) referred to differences in S. officinalis reproductive behaviour in the English Channel and the Bay of Biscay to support their assumption. In contrast to cuttlefish from the Mediterranean Sea, reproduction is clearly restricted to seasonal patterns in the Bay of Biscay and the English Channel due to climatic conditions. In the Adriatic Sea water temperatures of at least $12-13{ }^{\circ} \mathrm{C}$ throughout the year (Boletzky, 1983) do not elicit offshore winter migration. Reproduction of Mediterranean S. officinalis hence occurs throughout the year and temporal genetic heterogeneity can be as high as spatial genetic heterogeneity (Garoia et al., 2004). In the English Channel and Bay of Biscay, however, inshore water temperatures remain higher than $12-13{ }^{\circ} \mathrm{C}$ only for about 6 months/year (Boletzky, 1983) and reproduction is constrained to a few weeks in spring and summer. This rules out an extensive temporal heterogeneity as described for the panmictic S. officinalis in the Adriatic Sea (Garoia et al., 2004).

In the English Channel, a 2-year life cycle has been proposed for S. officinalis (Dunn, 1999). Reproduction is restricted to a period between February and July, the offspring of this generation hatch from July to September. At the time of hatching, the offspring from the previous year are also present in coastal waters, which due to the low temperatures in the Channel have not grown to maturity yet. Male individuals show first signs of sexual maturity in spring, while females mature later (until winter). In late autumn, winter migration sets in and this years' juveniles together with last years' offspring move to their overwintering areas. In spring, cuttlefish return to coastal waters, the now 2-year-old animals reproduce and then die (Dunn, 1999).

For the Bay of Biscay, two alternating biological cycles have been described by Le Goff and Daguzan (1991). Some individuals hatch early, show fast growth and have a short life 
span of only 1 year. Other individuals hatch later, exhibit slower growth and have a longer life span of 2 years (comparable to the English Channel individuals). Both groups regularly meet in winter migrations and reproduction of this years' early hatchlings and last years' late hatchlings only differs by a few weeks (Le Goff and Daguzan, 1991). This most probably allows for genetic exchange between both biological cycles known for the Biscay cuttlefish.

Tagging experiments by Boucaud-Camou and Boismery (1991) have shown that cuttlefish in the English Channel may return in spring to coastal waters different from where they have been tagged before. The authors do not provide information on the percentage of individuals involved and whether these animals were long- or short-lived. According to Le Goff and Daguzan (1991), cuttlefish in the English Channel never breed before they have performed two winter migrations; this augments the probability to finally lay eggs in different coastal waters.

Upon mating, spermatozoa may be stored in paired seminal receptacles of the female's buccal membrane over 4-8 weeks (but also up to 5 months in captivity (Hanlon et al., 1999)), until they are released for egg fertilization (Mangold, 1987). Females have also been shown to mate with multiple males and sperm competition is supposed to be a major feature of reproduction in S. officinalis (Hanlon et al., 1999).

As a consequence, there appears to be a rather wide temporal frame for sexually mature/maturing animals of both sexes from the English Channel and from the Bay of Biscay to mate in presumably common deep-water overwintering areas in the Hurd Deep (NW of the French Atlantic coast and W of the English Channel). This would provide an explanation for at least some genetic exchange between $S$. officinalis from the southern North Sea, the English Channel and the Bay of Biscay that is indicated by the microsatellite data presented here. A contribution of larval drift to such phenomena would be small as juveniles display adult features like flight behaviour, directed swimming and hunting within days after hatching (personal observations).

By means of microsatellite analysis, the present study provides further insight into the degree of population substructure and herewith gives new evidence for weakly structured populations and a substantial degree of genetic exchange of $S$. officinalis in its northernmost distribution range. Still, populations display a considerable degree of genetic variation that could explain for the biological differences found between individuals from the English Channel and the Bay of Biscay. It thus would be worth to further elucidate both population structure and physiology of the cuttlefish populations along the Atlantic coast in future studies.

\section{Acknowledgements}

The authors thank Marcos Pérez-Losada and Paul Shaw for providing us with microsatellite data for the Faro population and Antonio Sykes (Faro), Frank Melzner (Bremerhaven), Guy Claireaux (La Rochelle), Richard Stride (UK) and Jan van der Veen (Netherlands) for supplying us with live and preserved samples. Christoph Held's helpful comments on statistical analysis is also greatly appreciated. We also thank two anonymous reviewers for their highly constructive criticism of this work.
This study was supported by NERC Grant NERC/A/S/2002/ 00812 .

\section{References}

Balloux, F., Lugon-Moulin, N., 2002. The estimation of population differentiation with microsatellite markers. Mol. Ecol. 11, 155-165.

Barton, N.H., Slatkin, M., 1986. A quasi-equilibrium theory of the distribution of rare alleles in a subdivided population. Heredity 56, 409-415.

Boletzky, S.v., 1983. Sepia officinalis. In: Boyle, P.R. (Ed.), Cephalopod Life Cycles: Species Accounts, vol. 1

Boucaud-Camou, E., Boismery, J., 1991. The migrations of the cuttlefish (Sepia officinalis L) in the English Channel. In: Boucaud-Camou, E. (Ed.), The Cuttlefish, First International Symposium on the Cuttlefish Sepia. Centre de Publications de l'Université de Caen, Caen, France, pp. 179-189.

Cockerham, C.C., Weir, B.S., 1984. Covariances of relatives stemming from a population undergoing mixed self and random mating. Biometrics 40, $157-164$.

Denis, V., Robin, J.-P., 2001. Present status of the French Atlantic fishery for cuttlefish (Sepia officinalis). Fish. Res. 52, 11-22.

Dunn, M.R., 1999. Aspects of the stock dynamics and exploitation of cuttlefish, Sepia officinalis (Linnaeus, 1758), in the English Channel. Fisheries Res. 40, 277.

Gaggiotti, O.E., Lange, O., Rassmann, K., Gliddon, C., 1999. A comparison of two indirect methods for estimating average levels of gene flow using microsatellite data. Mol. Ecol. 8, 1513-1520.

Garoia, F., Guarniero, I., Ramsak, A., Ungaro, N., Landi, M., Piccinetti, C., Mannini, P., Tinti, F., 2004. Microsatellite DNA variation reveals high gene flow and panmictic populations in the Adriatic shared stocks of the European squid and cuttlefish (Cephalopoda). Heredity 93, 166-174.

Goodman, S.J., 1997. R-ST Calc: a collection of computer programs for calculating estimates of genetic differentiation from microsatellite data and determining their significance. Mol. Ecol. 6, 881-885.

Hanlon, R.T., Ament, S.A., Gabr, H., 1999. Behavioral aspects of sperm competition in cuttlefish, Sepia officinalis (Sepioidea: Cephalopoda). Mar. Biol. 134, 719-728.

Hardy, O.J., Charbonnel, N., Freville, H., Heuertz, M., 2003. Microsatellite allele sizes: A simple test to assess their significance on genetic differentiation. Genetics 163, 1467-1482.

Hartl, D., Clark, A., 1997. Principles of Population Genetics. Sinauer Associates, Sunderland, MA.

Kimura, M., Crow, J.F., 1964. The number of alleles that can be maintained in a finite population. Genetics 49, 725-738.

Kimura, M., Ohta, T., 1978. Stepwise mutation model and distribution of allelic frequencies in a finite population. Proc. Natl. Acad. Sci. U. S. A. 75, 2868-2872.

Kumar, S., Tamura, K., Nei, M., 2004. MEGA 3: Integrated software for Molecular Evolutionary Genetics Analysis and sequence alignment. Brief. Bioinform. 5, 150-163.

Le Goff, R., Daguzan, J., 1991. Growth and life-cycles of the cuttlefish Sepia officinalis L (Mollusca, Cephalopoda) in South Brittany (France). Bull. Mar. Sci. 49, 341-348.

Levene, H., 1949. On a matching problem arising in genetics. Ann. Math. Stat. 20, 91-94.

Mangold, K., 1966. Sepia officinalis from Catalonian Sea. Vie Et Milieu Serie ABiologie Marine 17, 961-1012.

Mangold, K., 1987. Reproduction. In: Boyle, P.R. (Ed.), Cephalopod Life Cycles: Comparative Reviews, vol. 2. Academic Press Inc, Orlando, Florida.

Melzner F., Langenbuch, M., Wolfram, K., Mark, F.C., Gutowska, M.A., Claireaux, G., Poertner, H.O. In vivo and in vitro blood oxygen binding in the cephalopod Sepia officinalis subjected to low temperatures, in preparation.

Miller, M.P., 1997. Tools for population genetic analysis (TFPGA) 1.3: A Windows program for the analysis of allozyme and moleculare population genetic data. Computer software available at http://evolution.genetics. washington.edu/phylip.html.

Nei, M., 1972. Genetic distance between populations. Am. Nat. 106, 283-292.

Nei, M., 1978. Estimation of average heterozygosity and genetic distance from a small number of individuals. Genetics $89,583-590$. 
Pawson, M., 1995. Biogeographical Identification of English Channel Fish and Shellfish Stocks. Ministry of agriculture fisheries and food, directionate of fisheries research, UK.

Pérez-Losada, M., Guerra, A., Carvalho, G.R., Sanjuan, A., Shaw, P.W., 2002. Extensive population subdivision of the cuttlefish Sepia officinalis (Mollusca: Cephalopoda) around the Iberian Peninsula indicated by microsatellite DNA variation. Heredity 89, 417-424.

Raymond, M., Rousset, F., 1995. Genepop (Version-1.2)-Population-Genetics software for exact tests and ecumenicism. J. Heredity 86, 248-249.

Rice, W.R., 1989. Analyzing tables of statistical tests. Evolution 43, 223-225.

Shaw, P.W., Pérez-Losada, M., 1999. Polymorphic microsatellites in the common cuttlefish Sepia officinalis (Cephalopoda). Mol. Ecol. 9, 237-238.

Slatkin, M., 1995. A measure of population subdivision based on microsatellite allele frequencies. Genetics 139, 457-462.
Valsecchi, E., Palsbøll, P., Hale, P., Glockner-Ferrari, D., Ferrari, M., Clapham, P., Larsen, F., Mattila, D., Sears, R., Sigurjonsson, J., Brown, M., Corkeron, P., Amos, B., 1997. Microsatellite genetic distances between oceanic populations of the humpback whale (Megaptera novaeangliae). Mol. Biol. Evol. 14, $355-362$.

Wang, J., Pierce, G.J., Boyle, P.R., Denis, V., Robin, J.-P., Bellido, J.M., 2003. Spatial and temporal patterns of cuttlefish (Sepia officinalis) abundance and environmental influences - a case study using trawl fishery data in French Atlantic coastal, English Channel, and adjacent waters. ICES J. Mar. Sci. 60, 1149-1158.

Wright, S., 1969. The Theory of Gene Frequencies. The University of Chicago Press, Chicago. 